\title{
Information Seeking and Online Deal Seeking Behavior
}

\author{
Weidong Zhang, Jilin University, Changchun, China \\ Xin Tian, Kennesaw State University, Marietta, USA \\ Wu He, Department of Information Technology and Decision Sciences, Old Dominion University, Norfolk, USA
}

\begin{abstract}
Deal-seeking behavior is booming over the last decade. This article aims to identify online deal-seeking resources, understand the current status of online deal-seeking and identify key insights and trends for understanding online deal seeker's behaviors. The authors first conducted an in-depth review of the relevant literature including white papers, survey reports, online news articles, as well as, numerous postings on multiple deal-seeking websites. Then, a blog mining approach is used to mine relevant blog posts they found from the Internet. The article identifies different types of online deal-seeking resources and summarizes key insights and trends for understanding online deal seeker's behaviors. Online deal seeking behavior is a subject that is not well explored. The article summarizes key insights and trends for understanding online deal seeker's behaviors. Information-seeking theories are used to help explain shopper's online deal-seeking behaviors.
\end{abstract}

\section{KEYWORDS}

Blog, Data Mining, Deal Information, Deal Seeking, Information Behavior, Online Information, Social Media, User Behavior

\section{INTRODUCTION}

The Internet has revolutionized global business and marketing. Numerous companies are actively using the Internet to market and sell their products and services on a global scale (He \& Wang, 2015). With the growing population of internet users globally, more and more people choose to shop online. Compared to offline shopping, online shopping has many advantages including saving transportation cost, easily comparing prices across different online stores and receiving more product information (Laudon \& Traver, 2013).

People who shop online include novice shoppers and savvy shoppers. It is noted that many savvy shoppers often search for deal information before they make online purchases. Searching for deals has become one of the most popular internet activities among today's consumers (Egol \& Lynch, 2010). According to a recent study by Market Track, $80 \%$ of respondents said they would do online price comparisons before making a purchase in a physical location (Renfrow, 2017). Many consumers even wait for the "deal" to become available before purchasing. 
Searching on the Web makes finding a great deal easy. Many online deal-related sites such as slickdeals.com and dealseeking.com are providing real-time daily deal information and moneysaving tips to shoppers. Shoppers can also use these sites to post deal information and share their deal-seeking skills and personal experiences about deals, hot bargains, discounts, coupons, rebates, pricing-errors, purchase process, product review and opinions and more with others (Gopal et al., 2006). Many "deal experts" have been sharing their knowledge for finding deals online. More and more consumers are learning how to find deals, how to save and they become more deal oriented. In addition, we have seen the influence of social media on people's deal seeking behavior. More and more people are using social media such as personal blogs, Google Docs, Facebook, Twitter and Foursquare to share and discuss the deal information. A survey from Empathica (2010) indicates that $60 \%$ of consumers follow a brand via social media, most because of coupons or promotions. Furthermore, in some countries, such as China and India, a lot of consumers tend to use mobile devices to seek and share deals.

Overall, today's consumers in many countries are becoming more strategic in their purchases and are leveraging various online resources to help them find the best deals and get the most savings. Deal-related resources can be found in many countries such as Taobao in China and eBay in the USA. These online deal-related resources provide a cost-effective way to disseminate deal information to a large audience in a short period of time and are driving more and more consumers' online shopping behavior to a large extent (Arnbert \& Rubinstein, 2012). Thus, it is important for companies to recognize and understand consumers' deal-seeking behaviors as well as the tremendous opportunities brought by leveraging the knowledge about consumers' deal-seeking behaviors (Sharma \& Khattri, 2013). Knowledge about consumers' deal-seeking behavior can help marketing managers design specific marketing strategies to appeal to deal prone households and increase the efficiency of distribution of coupons and other promotional items.

Information-seeking and deal-seeking are two common online activities people do with the Internet. Information researchers have studied extensively about the information-seeking behaviors of practitioners such as librarians, academics, teachers, doctors, engineers and lawyers (Andrews et al., 2005; Fisher, Erdelez, \& McKechnie, 2005). These studies have built the knowledge about the information needs of information seekers and the ways in which they think and behave to meet the information needs. However, so far there are few studies done on shoppers' online deal seeking behavior although online deal-seeking is a popular online activity for people across the world. Currently, online deal seeking behavior is a subject that is not well explored (Feng, 2008) although a few organizations or companies conduct annual shopper surveys for consumers in the USA, UK and other countries. To better understand how savvy shoppers who look for deals online for their purchase, we conducted an in-depth review of the relevant literature including white papers, survey reports, online news articles as well as numerous postings on multiple deal-seeking websites, Facebook, twitters and blogs including slickdeals.com, dealsea.com, dealseekingmom.com, and groupon.com. A blog mining approach is also used to mine the blog posts we found from the Internet. The study provides many insights for understanding today's online deal seeker's behaviors. A deep understanding of the deal-seeking behaviors of online shoppers could not only help information system developers develop better online shopping environment and deal-seeking resources, but also help global marketers to better determine their sales promotion strategies, build positive relationship with customers, increase brand awareness, enhance customer loyalty, identify and rectify issues, and more (Gopal et al., 2006).

This paper is organized as follows: Section 2 is a review of online deal-seeking resources. Section 3 describes the blog mining method we used for the study. Section 4 describes the findings. Section 5 discussed the results and implications, and summarizes insights and trends related to deal-seeking behaviors. Section 6 presents the conclusion and future research. 


\section{LITERATURE REVIEW}

Schade (2014) identified five types of e-commerce shoppers including product focused, browsers, researchers, bargain hunters and one-time shoppers:

- $\quad$ Product-focused shoppers know exactly what they want, and the goal is speed. They only want to locate the product, confirm it's the right one, and buy it;

- Browsers are leisurely shoppers who go to their favorite sites or new sites for inspiration or to kill time;

- Researchers are goal driven shopper. They plan to purchase, but the purchase may happen today, tomorrow, next week, or in six months. They're collecting information about products and prices and may be in any stage of research. Researchers may visit multiple sites to gather information before committing to a purchase;

- Bargain hunters look for the best deal possible. Some shoppers are simply looking for bargains, enticed into purchases by the idea of getting a good deal. Bargain-hunting behavior may impact any of the other types of shoppers;

- One-time shoppers may be product focused, browsing, bargain hunting, or researching. They may come with a goal in mind and they have no intentions to visit the site after the initial purchase; they are visiting due to a one-time need.

Furthermore, a study from Experian Marketing Services categorizes deal-seekers into six segments based on their attitudes, behaviors and motivations for deal-seeking. Table 1 describes the six categories and their characteristics.

Karande and Ganesh (2000) found that price/value, merchandise, recreational, time saving and deal seeking are main reasons why people shop at factory outlets. They identified three types of outlet mall shoppers - recreational shoppers, serious economic shoppers, and time conscious deal prone shoppers. Ganesh et al. (2010) further found that there are segments of online shoppers that are very similar to traditional offline shopper groups and there are more similarities than differences among traditional and online store shoppers. Chen, Schwartz and Vargas (2011) mentioned that deal-seeking travelers often continue to search after they have made a reservation, looking for an even better deal. If a better deal is found after they made their initial booking, these deal-seekers cancel their existing reservation and rebook the better deal. The Advanced Booking Decision Model outlined in Schwartz $(2006,2008)$ provides a theoretical decision-making framework to explore deal-seekers' search and booking behavior. The model indicates that the customer's assessment of the likelihood of a sellout and of the expected best offer affect the customer's propensity to book a hotel room. If deal-seeking consumers believe that future prices will be higher, they will accelerate their purchase. In addition,

Table 1. Deal-seeking consumer segmentation (cited from Experian, 2013)

\begin{tabular}{|l|l|}
\hline \multicolumn{1}{|c|}{ Deal-Seeking Consumer } & \multicolumn{1}{c|}{ Characteristics } \\
\hline Deal-Seeker Influentials & always seeking the best deal and the next hot thing \\
\hline Offline Deal-Seekers & seek best deals using traditional media \\
\hline Deal Thrillers & love their deals, but are brand loyalists too \\
\hline Deal Takers & social, but not influential \\
\hline Deal Indifferents & deal or no deal, give them what they want \\
\hline Deal Rejectors & get in, get out: convenience rules \\
\hline
\end{tabular}


price change patterns affect consumers' expectations and the propensity to book while the consumer is engaged in the search for a good deal. Dawra, Katyal, and Gupta (2015) pointed out that there is a difference between a deal-prone and a bargaining-prone customer. Deal-prone customers are value conscious and price mavens. Bargaining-prone customers are value-conscious price mavens and have a high need for special treatment (play).

The Internet has promoted deal-seeking behaviors and the creation of a deal-seeking culture (Schwartz, \& Chen, 2012). There are many online resources which are committed to share the latest deal information that meets the interest of online shoppers (Sharma \& Khattri, 2013; Shahzad et al., 2017; Vila, Vila, González, \& Brea, 2018). These online resources often contain sale information, links to printable coupons, coupon codes, rebate, etc. We reviewed a number of online deal-seeking resources. Based on our in-depth review and years of personal experience, we categorize these online resources into the following 10 types:

1. Deal forums such as slickdeal. These websites are free, user-driven deal sharing websites that provide consumers information with free discounts, promo codes, reviews and price comparisons so they can make more informed choices. Through the online forum, consumers post deal information and share their deal-seeking skills and personal experiences about deals, hot bargains, discounts, coupons, rebates, pricing-errors, purchase process, product review and opinions and more with others (Gopal et al., 2006). The websites do not sell products they list. Staff of the websites research deals and price and post the best deals on the front page. Consumers can register to the websites and receive the updates about deals via emails, RSS feeds, smart phone apps, or wish list they made;

2. Deal news websites such as Dealnews. These websites also report deals offered by thousands of merchants, and they do not sell any of the products they list. Different from those deal forum websites, the deals listed on these deal news websites come from a staff of writers who search the Internet daily to find the best deals available on a variety of products, rather than shared by consumers. Similarly, consumers can receive latest deal information through email alerts, newsletter, or RSS feeds;

3. Deal-of-the-Day websites such as Groupon, Newegg, and Google Offer, etc. These websites negotiate discounts with popular businesses on merchandises and services and send the sale information to their subscribed members by email, Facebook or tweeter feeds, and other RSS feeds. Usually, these sales are valid for a period of time (usually 24 hours). Customers purchase the deal from these websites rather than from suppliers or retailers of merchandise and/or services. These daily deal websites are appealing to consumers because they offer low price and deep discounts;

4. Gift card deal websites such as Plastic Jungle and Gift Card Granny: These websites sell merchants' gift cards for less than face value. They'll also buy gift cards consumers do not want for $80 \%$ to 90\% of the card's value (Huddleston, 2011);

5. Social media for deals such as Facebook for deal seeking mom, Hip2Save.com, Totallytarget. com, coupon consultant, and other social medial tools. These are personal blogs where savvy shoppers share deal information. By subscribing, consumers can receive daily deals information via email. These deal-seeking websites have the features to post real-time deals to the subscribers by email and push the notifications by mobile apps;

6. Mobile deal-seeking platform or apps such as Ibotta and WeChat. For example, people in china often use WeChat to post, share and seek deals. Many people also form groups to share and discuss deals through WeChat app;

7. Online market websites such as Amazon, Taobao and eBay. These websites provide an online marketplace where anyone can buy and sell practically anything. Consumers register an account so they can post stuffs they want to sell as well as buy stuffs from these websites; 
8. Rebate/Cashback websites such as ebates and shopDiscover. These websites also list coupons and products as previously listed types of deal websites. However, they provide cash back to the consumers who shop on their websites;

9. Local classifieds and forums such as Craigslist. These websites provide an online space for consumers and merchants post deals, local classifieds about jobs, housing, and services, etc. Consumers register their account, so they can post message to the online community. Not like Amazon and eBay, there is no business transactions occurred on these websites;

10. Contests and Sweepstakes sites such as Sear/Kmart's Shop Your Way program which offers sweepstakes, contests and instant win games for members to win points, prizes and giveaway.

The above literature review shows that although many deal-seeking resources are available and online deal seeking has become a widespread phenomenon, scholars have not yet addressed online deal seeking behavior adequately. Academy research and references to online deal seeking behaviors are rare.

\section{METHOD}

There are numerous blogs that provide various deal information. Many deal experts and consumers also post their deal-seeking tips on blogs. To further understand people's deal-seeking behavior, we employed a relatively novel research method called blog mining. This methodology has been shown to be very useful in information and internet-related studies because blogs are freely and publicly available online, and contents were created by self-motivated bloggers independently of the study (Rubin et al., 2011). An analysis of active blogs can add currency and relevancy to research studies (Chau \& Xu, 2012). For example, Chen (2014) applied blog mining to investigate MOOCs (massive open online course) and identified both positive and negative opinions related to MOOCs. Thus, blogs could be a very useful data source for learning about brands, trends, opinions, etc. A limitation with blog mining is that the information on blogs is not peer reviewed as journal publications and often represents personal opinions and attitudes. Due to the inherent anonymity of the internet, the authorship of some blog pages is either not clear or unknown. Some blog sources may be tied to vendors who have an agenda to promote their products or ideas. It is possible that some vendors may hire bloggers to write content to their benefit. Thus, researchers need to be careful of the inherent bias on blog posts when they analyze the content of blog posts. One way to mitigate this limitation is to combine blog mining with an extensive literature search for a more comprehensive understanding of the topics that are under investigation.

As the blog mining approach is relatively new to many readers, a detailed explanation is described as follows. First, we conducted query search with keywords such as deal-seeking and deal-seeking behavior, using several popular blog search engines including Google's blog search function, Blogspot Blog Search Engine (http://www.searchblogspot.com/), Blog Search Engine (http://www. blogsearchengine.org/) and Twingly Blog Search (https://www.twingly.com/search). Two researchers skimmed through nearly 190 blog posts returned by these search engines to check if the blog posts were relevant to our research interest. After examining and removing redundant and irrelevant blog posts, we identified 90 relevant blog posts for further analysis. These blog posts were saved as text files on the hard drive and were used as sample dataset which provided a glimpse into the ongoing trends associated with deal-seeking activities on the Internet. Next, we analyzed the blog posts using text mining techniques. Text mining is useful to analyze the qualitative data from online sources (Tian et al., 2016). Before we perform text mining techniques, we did pre-processing to clean all the space and special symbols in the dataset, such as "\&”, “@”, “!” and so on. We converted all the texts to lower cases and removed common words in each sentence, such as "a", "an", "the", "which" and so on. Because those common words do not have any analytic value, we use function "stopwords 
(English)" in R packages to eliminate those words. After the processing, we created a document term matrix and then started to explore the data.

The famous open source statistical software, R (https://www.r-project.org/)'s text mining package is used for analyzing word frequency (Joseph, Kar, Ilavarasan \& Ganesh, 2017). The word frequency analysis identified terms that appear frequently in these posts. Figure 1 shows the steps of a blog mining process.

\section{RESULTS}

Table 2 and Table 3 show some of the top words that were frequently used among all comments in our dataset. We removed the meaningfulness words and the most frequently words. Table 2 shows words with frequency is larger than 80 and Table 3 shows words with frequency is larger than 50 .

Furthermore, we used Leximancer (a well-known text analytics tool) to conduct cluster analysis. Leximancer produced several types of concept maps that indicated the extracted concepts from the sample data set and their interrelationships. Leximancer also generated a report that listed the themes and concept terms using its text analytics algorithms. Closely linked concepts are grouped into the same cluster. From the generated clusters by Leximancer, we were able to identify six meaningful themes which include study, deals, coupons, consumers, and shoppers. Table 4 shows the six clusters and corresponding concept terms.

Figure 1. Blog mining (adapted from Abdous \& He, 2011; Chen, 2014)

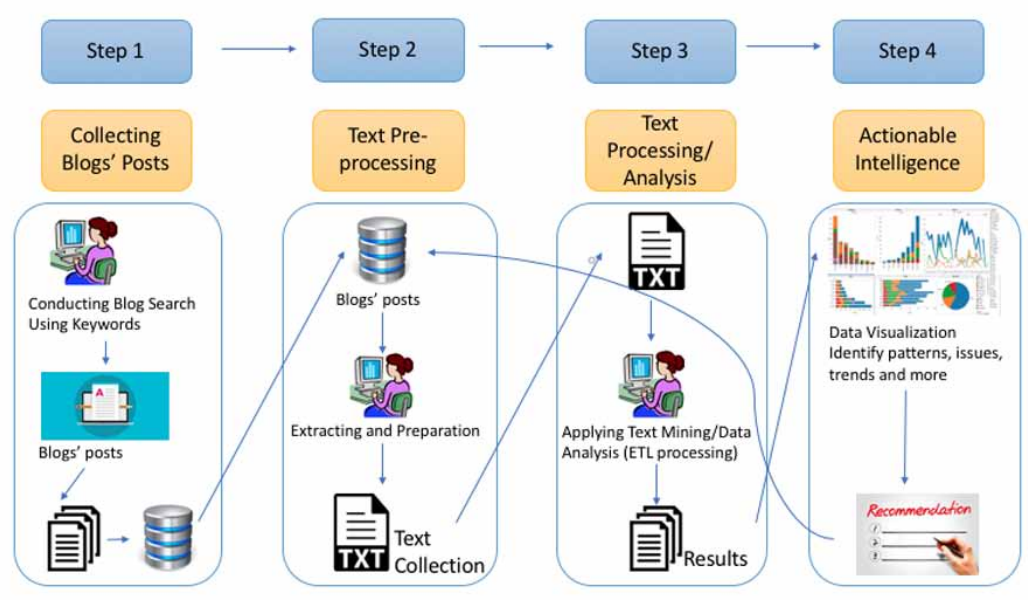

Table 2. Most frequently used words (frequency>80)

\begin{tabular}{|l|l|l|l|l|l|l|}
\hline behavior & consumers & coupons & deal & shopping & shoppers & study \\
\hline
\end{tabular}

Table 3. Most frequently used words (frequency>50)

\begin{tabular}{|l|l|l|l|l|l|l|}
\hline behavior & consumers & coupons & deal & shopping & shoppers & study \\
\hline deal-seeking & brands & mobile & online & percent & price & rebate \\
\hline savings & search & store & use & year & & \\
\hline
\end{tabular}


Table 4. Cluster of concepts

\begin{tabular}{|l|l|}
\hline \multicolumn{1}{|c|}{$\begin{array}{c}\text { Cluster of Concepts } \\
\text { (Theme) }\end{array}$} & \multicolumn{1}{c|}{ Concept Terms } \\
\hline study & study, survey, deal, behavior, shopper, price, deal-seeking, spending, habits \\
\hline deals & deals, shopping, search, daily, likely, compare, value, brands, holiday \\
\hline coupons & $\begin{array}{l}\text { coupons, discount, rewards, items, policy, strategy, promotions, want, rebate, savings, } \\
\text { download, print, clip, share, swap, redeem }\end{array}$ \\
\hline consumers & $\begin{array}{l}\text { consumers, shoppers, buyers, children, adults, millennials, older, seniors, women, men, baby } \\
\text { boomers, friends }\end{array}$ \\
\hline methods & $\begin{array}{l}\text { online, Web, media, mobile, paper, newspaper, stores, apps, email, circulars, coupons, } \\
\text { rebates, internet search, mail, fliers, alerts, print ads }\end{array}$ \\
\hline feeling/attitude & smart, engaged, happy, annoying, feel like winners, feel overcharged, enjoy \\
\hline
\end{tabular}

Table 5 shows some quotes of the themes.

Many of the blog posts report the insights or findings from various survey studies about the consumer behavior such as seeking deals or use coupons. We found summarized findings and statistics from different shopper survey studies through various blog posts (e.g., Carter, 2017). For example, a national online survey study in 2013 with 1,078 respondents in the US summarized their responses to a 50-question survey exploring their deal seeking behavior (Nanji, 2013). Some key findings posed on the blog include: deal-seeking increases over the years; people are willing to travel for savings; Facebook is the preferred digital channel for rebate deals.

As deal-seeking behavior is often related to search of best value, we specifically examined the keyword "value" and tried to find its correlated words. We found that "percent" is the most correlated word to "value". Shoppers discussed how many percent off was considered a good deal, or what percentage of discount they got. "prices" and "brands" were often mentioned in their discussion about the value of the goods. It looks like many shoppers were looking for deals by value. For example,

Table 5. Examples of the themes and representative quotes

\begin{tabular}{|l|l|}
\hline \multicolumn{1}{|c|}{ Theme } & \multicolumn{1}{c|}{ Representative Quotes } \\
\hline study & The shopper behavior study was conducted via a national online survey \\
\hline deals & $\begin{array}{l}\text { Deal-seeking behavior is booming: Before shopping, 90\% of consumers look online for the best } \\
\text { deals and 89\% look for sales, deals, cashback rebates and best advertised prices; } \\
\text { Demand for deals in social networks: 1 out of 3 shoppers would participate in a social media } \\
\text { contest to receive an exclusive cashback rebate; }\end{array}$ \\
\hline coupons & $\begin{array}{l}\text { Become familiar with the policies of your local store. For example, can you use } \\
\text { both a store coupon and a manufacturer s coupon on the same item? } \\
\text { More consumers are using mobile coupons and apps since last year. }\end{array}$ \\
\hline consumers & $\begin{array}{l}\text { Consumers advocate a great offer they've found to their friends; } \\
\text { consumers are getting a deal even if it's something the buyer doesn't really want; }\end{array}$ \\
\hline methods & $\begin{array}{l}\text { Savvy shoppers use both traditional and digital sources to garner the most savings; } \\
\text { shoppers use their smartphones in stores. }\end{array}$ \\
\hline feeling/attitude & $\begin{array}{l}\text { I feel smart when I find the best deal. } \\
60 \% \text { of consumers feel that shopping is competitive and getting a better price than others makes } \\
\text { them feel like winners; } \\
\text { enjoy taking the time to find bargains; } \\
\text { this is a win-win situation that makes everyone happy. }\end{array}$ \\
\hline
\end{tabular}


some high-end products frequently received a lot of discussion when they were on sale. Many dealseekers chose to monitor the products for a while until they were able to get a discount for their purchase. Deal-seekers are also less brand loyal and are more likely to buy items on sale rather than their preferred brands. Below is a quote we found from the data set:

\section{Millennials are also the most likely generation to buy over-the-counter medication and beauty/personal care items that are on sale rather than their preferred brand.}

In addition, coupons influence brand selection for some deal-seekers who may switch brand for a good sale or coupons. Many consumers become more social in their savings and share coupons and deals with family and friends regularly. Typical ways to get coupons include the newspaper, emails, retail circulars, Internet searches, mail, flyers and mobile phone (Fortin, 2000; Jayasingh, \& Eze, 2009). This result was confirmed by Blackhawk Network (2017)'s survey with 2001 people as sample size. Over $80 \%$ of respondents named price and quality are the top factors that affect their purchasing decisions. Respondents reported “... using their smartphones to check for deals (41 percent); looking for deals, rebates and advertised prices (27 percent); looking for deals in loyalty and reward programs (26 percent) and asking their personal network for deals ( 22 percent)..."

At last, we looked into the statistics and survey findings from some blog posts we found (e.g., Nanji, 2013; Carter, 2017) and summarized some relevant insights and trends related to deal-seeking behavior. The summarized insights and trends are listed in Table 6 .

Table 6. Insights and trends related to deal-seeking behaviors

\begin{tabular}{|c|c|}
\hline Pattern & Insights and Trends \\
\hline $\begin{array}{l}\text { Deal-seeking behavior } \\
\text { is booming }\end{array}$ & $\begin{array}{l}\text { - Deal-seeking behavior is increasing regardless of age or income. } \\
\text { - Consumers are willing to work harder and take more time to seek deals. } \\
\text { - Holiday shopping season is typically the most active time of year for deal seeking. }\end{array}$ \\
\hline $\begin{array}{l}\text { Seek deals using } \\
\text { multiple resources }\end{array}$ & $\begin{array}{l}\text { - Consumers are leveraging both offline and online resources to look for deals. } \\
\text { - Increased use of mobile devices and mobile coupons for deals (Liu et al, 2015). }\end{array}$ \\
\hline $\begin{array}{l}\text { Discussion about } \\
\text { Gender }\end{array}$ & $\begin{array}{l}\text { - Women represent the highest usage of coupons. When shopping online, women are more } \\
\text { prone to use coupons then men; Men are more prone to use coupons for electrical items and } \\
\text { computers (Harmon \& Hill, 2003) } \\
\text { - Male consumers were likely influenced by emotional gratification, such as feeling excited } \\
\text { about finding a good deal online. Alternatively, female consumers were not influenced by } \\
\text { affection but by their cognitive evaluation (Chen, Phelan, \& Jai, 2016). }\end{array}$ \\
\hline Discussion about Age & $\begin{array}{l}\text { - Age has a more significant impact on coupon usage for women than for men. } \\
\text { - Older women are more prone to use coupons for groceries and in-store items than younger } \\
\text { women; } \\
\text { - Millennials who have below-average incomes tend to engage more in deal-seeking behavior. }\end{array}$ \\
\hline Use of coupons & $\begin{array}{l}\text { - Deal-seeking behavior is increasingly seen in the use of coupons. } \\
\text { - Many shoppers expand their coupon hunting from traditional newspaper circulars to include } \\
\text { various online resources. } \\
\text { - Coupons also prompt many shoppers to buy items or visit a store that they otherwise } \\
\text { wouldn't. } \\
\text { - Coupon policy of individual stores is often discussed in online forums. } \\
\text { - Many deal-seekers share coupons with friends through social networks, coupon trading } \\
\text { groups and other channels }\end{array}$ \\
\hline Complaints/Issues & $\begin{array}{l}\text { - Overspending. It becomes a problem when consumers overspend or buy things they don't } \\
\text { even need. Coupons encourage consumers to spend more. } \\
\text { - Keep track of coupons or deals. It takes time to keep track of deals and coupons. People } \\
\text { often missed the deals or forgot to use coupons before the expiration date. }\end{array}$ \\
\hline
\end{tabular}




\section{DISCUSSION}

The results show that more and more people are engaged in deal-seeking behavior in order to get more value for the same price or pay less for the same amount. Deal-seeking is similar to information seeking in many aspects because the majority of deal-seekers are actively engaged in a deliberate process of information search that is designed to identify the ways to obtain the best deals. Similar to the information-seeker, deal-seekers experience the search process as an interplay of thoughts, feelings and actions (Kuhlthau, 2004). According to Wilson (2000), information seeking behavior is the purposive seeking for information as a consequence of a need to satisfy some goal. In the context of deal-seeking, seeking information is also paramount. The goal of most deal-seekers is to get the best deal or value by stretching their dollars in a way they deem valuable and/or save money for the items they need although some deal-seekers also consider searching the websites for deals more of a way of having fun (Scarpi, Pizzi, \& Visentin, 2014). Deal-seeking is also different from knowledge seeking. Lai and Graham (2009) argue that knowledge seeking is about people who construct knowledge through problem solving and experiential learning. Knowledge seekers typically construct knowledge when they encounter problems and thus knowledge seeking is essentially a learning process. As for deal-seeking, paying less than others for the same products is a driving motive for many deal-seekers, which relates to individual feelings of felling like winners, pleasure, pride and victory. As a survey study by Yahoo!/UM (2011) shows, “...60\% of consumers feel that shopping is competitive and getting a better price than others makes them feel like winners..." Another study by Webolutions (2011) shows that $51 \%$ of consumers feel slighted and/or annoyed when they have to pay full price for an item. The study also found that consumers feel excited and/or happy about clipping coupons. On the contrary, when a deal is missed, deal-seekers often experience a negative feeling such as disappointment, frustration, anxiety and irritation. Studies show that daily deal websites represent an especially tempting shopping context for compulsive buyers (Kukar-Kinney, Scheinbaum, \& Schaefers, 2016).

The analysis of the blogs found that deal-seekers are leveraging various tools and resources to help them find the best deals and get the most savings. They become less impulsive in their shopping and take the time to do research before making a decision (Yahoo!/UM, 2011). As the study by Yahoo!/ UM (2011) describes, they use different tools throughout the shopping process to discover deals that fits their needs, evaluate the deals through price comparison sites in order to find the best value for their money, and also use social media tools to get trustworthy feedback to make smarter decisions faster. This phenomenon aligns with the well-known model of information search process proposed by Kuhlthau (1993). There are six primary tasks to be accomplished in the search process: initiation, selection, exploration, formulation, collection and presentation (Kuhlthau, 1993). A significant finding of Kuhlthau's research is the relative uncertainty the information seekers feel throughout the process. This principle of uncertainty proves to be a determination in the success or failure of the information seeker's efforts. Kuhlthau's model can be applied to help understand the deal-seeking behavior as well. As deal seekers move through various stages in the search process to find the best deals, they often need to select the product, explore the product, evaluate the deals, compare product prices or performance, seek additional information, select the information and finally use information to satisfy his/her information needs for learning more about the deals. For example, they may check online consumer reviews from forums or social media platforms and use the information to help with their decision making. Deal seekers experience uncertainty in their deal search process, particularly when they encounter contradictory information about the products or deals. When there is a shortage of information, they may ask questions on online forums to seek additional comments and experience from previous buyers in order to reduce uncertainty. Deal-seekers benefit from online reviews by other customers. They can read those reviews before they make a decision (Sharma \& Khattri, 2013). In the case of great uncertainty, many deal-seekers are willing to wait until they find enough information to help them make decisions. It is observed that some deal-seekers spend months tracking prices and 
waiting for a bargain. In some cases, deal-seekers may also choose to purchase the deal first and then cancel it if they are able to find a better deal later (Chen, Schwartz, \& Vargas, 2011).

Consumers show varying information needs, behaviors and attitudes to deals (Prasad \& Aryasri, 2009). Although many deal-seekers especially millennials are price sensitive, price isn't the most important factor for other deal-seekers. The growth of various deal-seeking sites and price comparison sites make shoppers believe that it is "cool" to find great deals. A study by Yahoo!/UM (2011) found that online deal-seeking makes shoppers look technically savvy and smart. A majority of the surveyed consumers said that finding a great deal make them feel like a winner. A survey report from Blackhawk Network (2017) indicates that shopping for deals provides shoppers with emotional satisfaction. About $40 \%$ of respondents said they feel smart when they can find the best deals.

Deal-seeking behavior has been reported throughout the three stages of shopping: before, during and after the shopping process. Customers do their research before shopping and after shopping (Blackhawk Network, 2017). For example, shoppers look for deals through loyalty and reward programs and review circulars and print ads. Some blogs and forums post the store circulars ahead of one or two weeks. For example, iheartcvs.com regularly posts circulars of CVS for next week. Shoppers review the circular early and make plan for the shopping trip including matching the coupons they have on-hand and see if they need to print the coupons online to get the most discounts. Even after shopping, savvy shoppers will search for rebates for the items they bought or compare the new prices with what they paid for. Customers may post their experiences on social websites like twitter and Facebook. Retailers or manufacturers can collect the twitter or Facebook data related to their brands or products and take advantage of social media platform to gain the competitive intelligence (He et al., 2015; He et al., 2016).

Wilson (2000) also point out information behavior as the totality of human behavior in relations to sources and channels of information, including both active and passive information seeking and information use. From this perspective, we can also dive deal-seekers into two types: active dealseekers and passive deal-seekers. Deal-seekers who primarily browse the deals at a particular deal site can be viewed as passive deal-seekers. For example, some shoppers only browse a particular daily deal site. They don't actively search for deals from multiple sites in order to save time. The Principle of least effort (Case, 2015) explains that information seekers priorities the most convenient path to acceptable information. The same principle can also be applied to explain the behavior of passive deal-seekers because looking at multiple websites each day takes a lot of time. Connaway, Dickey, and Radford (2011) confirm that convenience is a factor for making choices in a variety of situations, including both academic information seeking and everyday-life information seeking. In contrast, those who look for deals using difference means such as multiple deal sites, emails, online chat tools and social media are active deal-seekers because they will actively use information they found to find the best deals (Arnbert \& Rubinstein, 2012). It is observed that active deal-seekers are chatting and discussing new offered deals on the Internet as soon as they are announced.

Researchers have identified factors affecting information source selection in different information seeking situations (Lee, Paik, \& Joo, 2012). Accessibility, availability, convenience, ease of use, accuracy, timeliness and reliability are among the most frequently discussed factors (Xie \& Joo, 2009). We think these factors are also important factors for the selection of online deal-seeking resources by deal-seekers. The owners of the online deal-seeking resources need to work on these factors in order to make their sites more popular.

The paper deals with an interesting but not well explored topic. The results could have implications on practice and society by getting a better understanding of online deal shopping behavior. Marketers can benefit from such insights to use online deal seeking resources and behavior to drive more sales and revenue. More and more retailers are increasingly responding to the deal-seeking shoppers. In particular, on Black Friday and Cyber Monday (the biggest best-selling season of the year), retailers often take advantages of deal-seeking forums and blogs to promote their products. Some retailers or vendors posted coupon policies on their websites and deal-seeking platforms to assist deal-seekers 
and clear confusion. Marketers may choose to respond to the deal-seeking culture and leverage attractive promotions and strategy to turn deal-seeking shoppers into loyal shoppers and help retailers and manufacturers improve sales. On the other hand, marketers don't need to waste their time and resources to send coupons or deals to those who are not interested in deals or reject deals. The results give insights on shopping behavior of e-commerce users and the influence of deals on that behavior. Marketing activities are needed to increase awareness about deal websites' offerings (Sharma \& Khattri, 2013). Research on deal-seeking behaviors also has implications on system designers and developers. An understanding about different types of e-commerce shoppers' deal-seeking behavior may help designers and developers to create more useable and flexible systems, tools, services and online resources to facilitate deal dissemination and sharing while supporting different users' needs.

\section{CONCLUSION}

The Internet has emerged as a major venue for price-conscious consumers to search for the best available deals. More and more people are becoming deal oriented and are increasingly using the Internet to look for better deals for savings. A study found that 62 percent of shoppers engage in at least one digital deal activity for half or more of their shopping trips (Egol \& Lynch, 2010). Savvy shoppers are willing to take time and efforts to find the best deals by using different means in an attempt to better "play the system" to their own advantage (Chen, Schwartz, \& Vargas, 2011).

The online deal-seeking resources we introduced in section 2 are being increasingly used by consumers in many countries to find and share deal-related information. These online deal-seeking resources promote the culture of deal seeking and the expectation for finding the best deals online (Chen, 2009). The results of the study reveal status, trends and concerns of English-speaking consumers in deal-seeking. A better understanding of deal-seeking behavior of consumers can help develop better deal-seeking resources and enable global marketers to more effectively take advantage of online dealseeking resources in different countries and technological advances to increase sales and revenue.

Studies on different types of deal-seekers' information seeking behavior are recommended in future research. For example, it is worthwhile to model gender-based customer preferences and online deal-seeking behavior (Khatwani, \& Srivastava, 2017). There are also five main types of e-commerce shoppers (Schade, 2014) who have different motivations and habits in terms of deal-seeking. It would be interesting to further study the influence of deals on their respective behavior. Furthermore, as there are so many different types of deal-seeking websites, it becomes important to find out how shoppers select their favorite deal-seeking websites and the factors that influence their selection. We plan to do a survey study with online shoppers to find out how they select deal-seeking websites. Im, Jun, Oh, \& Jeong (2016) hypothesize that deal-seeking keywords elicit a search of greater breadth and they find out 1) search queries containing deal-seeking keywords are associated with higher click-through rates and conversion rates than are search queries without such keywords; 2) the positive effect of deal-seeking keywords on click-through rates is more pronounced for experience goods than for search goods. We plan to conduct more research on deal-seeking keywords in the future to identify further insights. We would like to conduct empirical studies to better understand savvy shoppers "visual guilt". A study found that people who go online and book the travel themselves feel guilty if they do not find a better deal compared to people who do it through travel agents, and named this phenomenon the "visual guilt" (McCartney, 2006). We will survey and interview savvy shoppers to better understand their mental models, emotions and behaviors for deal-seeking.

\section{ACKNOWLEDGMENT}

This research was supported by the International Innovation Team of Philosophy and Social Science of Jilin University. 


\section{REFERENCES}

Abdous, M., \& He, W. (2011). Using text mining to uncover students' technology-related problems in live video streaming. British Journal of Educational Technology, 40(5), 40-49. doi:10.1111/j.1467-8535.2009.00980.x

Andrews, J. E., Pearce, K. A., Ireson, C., \& Love, M. M. (2005). Information-seeking behaviors of practitioners in a primary care practice-based research network (PBRN). Journal of the Medical Library Association: JMLA, 93(2), 206. PMID: 15858623

Arnbert, C., \& Rubinstein, Y. (2012). What's the deal? - a study of the underlying motives for looking at and buying daily deals online [Bachelor Thesis]. University of Gothenburg.

Blackhawk Network. (2017). Hawk Incentives Research: Deal Seeking on the Rise; Shoppers Report These Behaviors Make Them Feel Smarter. Retrieved from https://www.multivu.com/players/English/8181551-hawkincentives-deal-seeking-shoppers/

Carter, B. (2017). Coupon Statistics: The Ultimate Collection. Retrieved from https://blog.accessdevelopment. com/ultimate-collection-coupon-statistics

Case, D. O. (2005). Principle of least effort. In K. E. Fisher, S. Erdelez, \& L. McKechnie (Eds.), Theories of Information Behavior (pp. 289-292). Medford, NJ: Information Today.

Chau, M., \& Xu, J. (2012). Business intelligence in blogs: Understanding consumer interactions and communities. Management Information Systems Quarterly, 36(4), 1189-1216.

Chen, C. C. (2009). What can revenue-optimizing firms do about their deal-seeking consumers: The role of price patterns, timing and cancellation policies in travelers' advanced booking decisions. Unpublished doctoral dissertation. University of Illinois at Urbana-Champaign.

Chen, C. C., Schwartz, Z., \& Vargas, P. (2011). The search for the best deal: How hotel cancellation policies affect the search and booking decisions of deal-seeking customers. International Journal of Hospitality Management, 30(1), 129-135. doi:10.1016/j.ijhm.2010.03.010

Chen, H., Phelan, K. V., \& Jai, T. M. (2016). Gender differences in deal hunting: What motivates consumers to search and book hotel deals? Journal of Hospitality Marketing \& Management, 25(5), 613-639. doi:10.1080/19368623.2015.1067666

Chen, Y. (2014). Investigating MOOCs through blog mining. The International Review of Research in Open and Distributed Learning, 15(2). doi:10.19173/irrodl.v15i2.1695

Connaway, L. S., Dickey, T. J., \& Radford, M. L. (2011). "If it is too inconvenient I'm not going after it:" Convenience as a critical factor in information-seeking behaviors. Library \& Information Science Research, 33(3), 179-190. doi:10.1016/j.lisr.2010.12.002

Dawra, J., Katyal, K., \& Gupta, V. (2015). “Can you do something about the price?”-Exploring the Indian deal and bargaining-prone customer. Journal of Consumer Marketing, 32(5), 356-366. doi:10.1108/JCM-09-2014-1158

Egol, M., \& Lynch, B. (2010). Shopper Marketing 4.0 Building Scalable Playbooks That Drive Results. Retrieved from https://www.gmaonline.org/downloads/research-and-reports/Shopper_Marketing_4.0.pdf

Empathica. (2010). Study: 60\% of Consumers Follow a Brand via Social Media, Most Because of Coupons or Promotions. Retrieved from http://www.inmoment.com/press/study-60-of-consumers-follow-a-brand-via-socialmedia-most-because-of-coupons-or-promotions/

Experian. (2013). 2013 Holiday hot sheet: weekly insights for the holiday marketer. Retrieved from https://www. experian.com/assets/marketing-services/product-sheets/wk4-holiday-hot-sheet.pdf

Feng, W. (2008). Online Consumer Behavior and Search Costs on Deal Seeking Forums [Doctoral dissertation]. University Of California, Berkeley.

Fisher, K. E., Erdelez, S., \& McKechnie, L. (Eds.). (2005). Theories of information behavior. Information Today, Inc.

Fortin, D. R. (2000). Clipping coupons in cyberspace: A proposed model of behavior for deal-prone consumers. Psychology and Marketing, 17(6), 515-534. doi:10.1002/(SICI)1520-6793(200006)17:6<515::AIDMAR5>3.0.CO;2-B 
Ganesh, J., Reynolds, K. E., Luckett, M., \& Pomirleanu, N. (2010). Online shopper motivations, and e-store attributes: An examination of online patronage behavior and shopper typologies. Journal of Retailing, 86(1), 106-115. doi:10.1016/j.jretai.2010.01.003

Gopal, R. D., Pathak, B., Tripathi, A. K., \& Yin, F. (2006). From Fatwallet to eBay: An investigation of online deal-forums and sales promotions. Journal of Retailing, 82(2), 155-164. doi:10.1016/j.jretai.2006.02.002

Harmon, S. K., \& Jeanne Hill, C. (2003). Gender and coupon use. Journal of Product and Brand Management, 12(3), 166-179. doi:10.1108/10610420310476924

He, W., Shen, J., Tian, X., Li, Y., Akula, V., Yan, G., \& Tao, R. (2015). Gaining competitive intelligence from social media data: Evidence from two largest retail chains in the world. Industrial Management \& Data Systems, 115(9), 1622-1636. doi:10.1108/IMDS-03-2015-0098

He, W., Tian, X., Chen, Y., \& Chong, D. (2016). Actionable social media competitive analytics for understanding customer experiences. Journal of Computer Information Systems, 56(2), 145-155. doi:10.1080/08874417.20 16.1117377

He, W., \& Wang, F. K. (2015). A hybrid cloud model for cloud adoption by multinational enterprises. Journal of Global Information Management, 23(1), 1-23. doi:10.4018/jgim.2015010101

Huddleston, C. (2011). 15 Web Sites for Finding Deals Online. Retrieved from http://www.kiplinger.com/features/ archives/21-web-sites-for-finding-deals-online.html

Im, I., Jun, J., Oh, W., \& Jeong, S. O. (2016). Deal-seeking versus brand-seeking: Search behaviors and purchase propensities in sponsored search platforms. Management Information Systems Quarterly, 40(1), 187-203. doi:10.25300/MISQ/2016/40.1.08

Jayasingh, S., \& Eze, U. C. (2009). An empirical analysis of consumer behavioural intention towards mobile coupons in malaysia. International Journal of Business and Information, 4(2), 221-242.

Joseph, N., Kar, A. K., Ilavarasan, P. V., \& Ganesh, S. (2017). Review of discussions on Internet of Things (IoT): Insights from Twitter analytics. Journal of Global Information Management, 25(2), 38-51. doi:10.4018/ JGIM.2017040103

Karande, K., \& Ganesh, J. (2000). Who shops at factory outlets and why?: An exploratory study. Journal of Marketing Theory and Practice, 8(4), 29-42. doi:10.1080/10696679.2000.11501878

Khatwani, G., \& Srivastava, P. R. (2017). Modeling gender based customer preferences of information search channels. Journal of Global Information Management, 25(2), 52-67. doi:10.4018/JGIM.2017040104

Kuhlthau, C. (2004). Seeking Meaning: a process approach to library and information services. London: Libraries Unlimited.

Kuhlthau, C. C. (1993). A principle of uncertainty for information seeking. The Journal of Documentation, 49(4), 339-355. doi:10.1108/eb026918

Kukar-Kinney, M., Scheinbaum, A. C., \& Schaefers, T. (2016). Compulsive buying in online daily deal settings: An investigation of motivations and contextual elements. Journal of Business Research, 69(2), 691-699. doi:10.1016/j.jbusres.2015.08.021

Lai, H., \& Graham, M. (2009). Knowledge Seeking in KM - Towards an Adapted KM Cycle. In Proceedings of ECKM 2009 in the 10th European Conference on Knowledge Management, Vicenza, Italy, September 03-04.

Laudon, K. C., \& Traver, C. G. (2013). E-commerce. Pearson.

Lee, J. Y., Paik, W., \& Joo, S. (2012). Information resource selection of undergraduate students in academic search tasks. Information Research: An International Electronic Journal, 17(1).

Liu, F., Zhao, X., Chau, P. Y., \& Tang, Q. (2015). Roles of perceived value and individual differences in the acceptance of mobile coupon applications. Internet Research, 25(3), 471-495. doi:10.1108/IntR-02-2014-0053

McCartney, S. (2006). Exploiting travelers' 'Visual Guilt': Firms find that employees pinch pennies if they book business trips themselves. Retrieved from https://www.wsj.com/articles/SB115378413105015902 
Nanji, A. (2013). Consumer price sensitivity and deal seeking up in 2013. Retrieved from http://www. marketingprofs.com/charts/2013/10833/consumer-price-sensitivity-and-deal-seeking-up-in-2013

Prasad, C. J., \& Aryasri, A. R. (2009). Determinants of shopper behaviour in e-tailing: An empirical analysis. Paradigm, 13(1), 73-83. doi:10.1177/0971890720090110

Renfrow, J. (2017). 80\% of shoppers compare prices online before shopping in stores. Retrieved from http:// www.fierceretail.com/digital/80-shoppers-do-online-price-comparison-before-store-shopping

Rubin, V. L., Burkel, J., \& Quan-Haase, A. (2011). Facets of serendipity in everyday chance encounters: A grounded theory approach to blog analysis. Information Research: An International Electronic Journal, 6(3).

Scarpi, D., Pizzi, G., \& Visentin, M. (2014). Shopping for fun or shopping to buy: Is it different online and offline? Journal of Retailing and Consumer Services, 21(3), 258-267. doi:10.1016/j.jretconser.2014.02.007

Schade, A. (2014). Designing for 5 Types of E-Commerce Shoppers. NN Group. Retrieved from https://www. nngroup.com/articles/ecommerce-shoppers/

Schwartz, Z. (2006). Advanced booking and revenue management: Room rates and the consumers' strategic zones. International Journal of Hospitality Management, 25(3), 447-462. doi:10.1016/j.jjhm.2005.02.002

Schwartz, Z. (2008). Time, price and advanced booking of hotel rooms. International Journal of Hospitality \& Tourism Administration, 9(2), 128-146. doi:10.1080/15256480801907885

Schwartz, Z., \& Chen, C. C. (2012). Hedonic motivations and the effectiveness of risk perceptions-Oriented revenue management policies. Journal of Hospitality \& Tourism Research (Washington, D.C.), 36(2), 232-250. doi: $10.1177 / 1096348011413589$

Shahzad, B., Lali, I., Nawaz, M. S., Aslam, W., Mustafa, R., \& Mashkoor, A. (2017). Discovery and classification of user interests on social media. Information Discovery and Delivery, 45(3), 130-138. doi:10.1108/IDD-03-2017-0023

Sharma, N. V., \& Khattri, V. (2013). Study of online shopping behavior and its impact on online deal websites. Asian Journal of Management Research, 3(2), 394-405.

Tian, X., He, W., Tao, R., \& Akula, V. (2016). Mining Online Hotel Reviews: A Case Study from Hotels in China. In Proceedings of AMCIS 2016, San Diego, CA.

Vila, T. D., Vila, N. A., González, E. A., \& Brea, J. A. F. (2018). The Role of the Internet as a Tool to Search for Tourist Information. Journal of Global Information Management, 26(1), 58-84. doi:10.4018/JGIM.2018010104

Webolutions (2011). Current Marketing Trend: Consumers Demanding Value. Retrieved from https://www. webolutions.com/996/

Wilson, T. D. (2000). Human information behavior. Informing Science, 3(2), 49-56. doi:10.28945/576

Xie, I., \& Joo, S. (2009). Selection of information sources: Types of tasks, accessibility and familiarity of sources. Proceedings of the American Society for Information Science and Technology, 46(1), 1-18. doi:10.1002/ meet.2009.1450460215

Yahoo. Universal McCann. (2011). Long and Winding Road: Gamesmanship of Shopping. Retrieved from https:// umcuriousthoughts.files.wordpress.com/2011/06/the-long-and-winding-road-gamesmanship-of-shopping-snapshot.pdf

Weidong Zhang, an associate professor in Department of Information Management in the School of Management at Jilin University, China, received PhD in Information Science from Jilin University. Research interests: Information Resources Management, Data Mining, Data Analysis and Information Delivery.

Xin Tian, Assistant Professor of Information Technology at Kennesaw State University. She received her PhD from Old Dominion University in 2018. Research interests: social media, data mining, and cybersecurity.

Wu He, an associate professor in Department of Information Technology and Decision Sciences at Old Dominion University, USA, received PhD in Information Science from University of Missouri, Columbia. Research interests: cybersecurity, social media analytics and learning analytics, data mining and text mining. 